\title{
GEODERMA
}

Geoderma $80(1997) 181-194$

\section{The influence of slope angle on final infiltration rate for interrill conditions}

\author{
D.M. Fox ${ }^{\mathrm{a}, *}$, R.B. Bryan ${ }^{\mathrm{b}}$, A.G. Price ${ }^{\mathrm{c}}$ \\ "Ecole Supérieure d'Agriculture de Purpan, Département d'Agronomie, 75 voie du T.O.E.C., \\ 31076 Toulouse Cedex, France \\ ${ }^{\mathrm{b}}$ Soil Erosion Laboratory, Division of Physical Sciences, Scarborough College, University of \\ Toronto, 1265 Military Trail, Scarborough, ON, Toronto, MIC IA4, Canada \\ ${ }^{\mathrm{c}}$ Environmental Science, Division of Physical Sciences, Scarborough College, University of \\ Toronto, 1265 Military Trail, Scarborough, ON, Toronto, MIC 1A4, Canada
}

Received 13 December 1995; accepted 4 June 1997

\begin{abstract}
Despite numerous studies, the relationship between slope angle and infiltration rate remains unclear. Under different experimental conditions, new processes may be introduced which influence the relationship. The presence of rills, for example, may significantly affect the relationship between slope angle and infiltration rate, so distinct relationships may exist for rill and interrill areas. The objective of this study was to investigate the influence of slope angle on infiltration rate for an interrill area with a surface crust. The experiment was carried out in a laboratory using simulated rainfall and soil trays designed to limit the processes to those found in interrill areas. Slope angles ranged from $1.5^{\circ}$ to $21.5^{\circ}$ : infiltration was calculated from the overland flow rate, and microtensiometers and micromorphological analysis were used to characterise the seals. Infiltration rate decreased with increasing slope angle; image analysis of pore characteristics in the affected layer and subseal pressure head measurements indicated there were no differences in seal characteristics between slope angles. The results showed that sealing intensity did not vary with slope angle, and the dominant influence of slope angle on infiltration rate resulted from changes in overland flow depth and surface storage. The results also suggest that small changes in seal hydraulic conductivity with microrelief play an important role in the infiltration process. (C) 1997 Elsevier Science B.V.
\end{abstract}

Keywords: infiltration; slope angle; surface crusting; interrill conditions

\footnotetext{
* Corresponding author. E-mail: fox@esa-purpan.fr
} 


\section{Introduction}

Contradictory observations have been made regarding the influence of slope angle on infiltration: infiltration rates have been observed to increase, decrease, or remain unchanged with changing slope angle. Slope angle influences several critical factors affecting the infiltration process; these include surface storage, effective rainfall intensity, and overland flow depth. For a given surface roughness, maximum surface storage capacity and mean ponding pressure head would decrease with increasing slope angle, and infiltration rate would therefore also be expected to decrease. Increasing trends may result when other processes (e.g. surface crust removal by rill incision etc.) intervene and become the dominant influence on infiltration. Such cases have been observed to occur in soils sensitive to surface sealing (Poesen, 1984).

Surface sealing is a physical and physico-chemical process of aggregate breakdown and/or coalescence and subsequent compaction and/or deposition under conditions of rapid wetting or raindrop impact (West et al., 1992). Raindrop impact compacts the thin surface layer into a 'structural crust' and the deposition of detached particles in micro-depressions forms 'depositional crusts.' The crust or surface seal is a layer at the surface of much lower hydraulic conductivity than the soil beneath it. Its presence reduces infiltration substantially.

Infiltration rate (except where noted otherwise, infiltration rate refers to the final equilibrium rate) was observed to increase with increasing slope angle for a silty loam prone to surface crusting (Poesen, 1984). One explanation for this was that surface sealing was less developed on steeper slopes due to the higher impact angle of falling raindrops and the greater erosion rates. It was also noted that rills had formed in the surface, and there was a positive correlation between slope angle and rill depth. The increase in infiltration rate may equally have resulted from more extensive breaching of the seal by rills on the steeper slopes, as Poesen (1984) also suggests.

Bradford and Huang (1992) found that infiltration rate increased with increasing slope angle for 1 of 4 soils and stated that the relationship is probably soil-specific. The determining characteristic influencing the relationship was cited as being the susceptibility to surface sealing. Infiltration rate increased with slope angle for the soil most susceptible to surface sealing. The process responsible for the increase, however, remained unclear. The authors observed more extensive rilling on the steeper slope. Bryan and Poesen (1989) observed an increase in infiltration rate where rilling incised through the surface seal. It is possible therefore that infiltration increases with slope angle only where rill development is associated with increasing slope angle.

Decreasing infiltration rate with increasing slope angle has commonly been observed in the field in soils from different parts of the world (Nassif and Wilson, 1975; Djorovic, 1980; Sharma et al., 1983). In a controlled field 
experiment, Luk et al. (1993) used simulated rainfall to examine the influence of slope angle on infiltration in a loess soil that was prone to crusting. For storms of short duration, infiltration rate increased with increasing slope angle, but for longer storms, the reverse occurred and infiltration rate decreased with increasing slope angle. The authors identified both a 'crust' and a 'slope' effect. The terms were not defined specifically, but it was understood that the crust effect was related to the hydraulic conductivity of the seal, and the slope effect was the influence of slope angle on overland flow depth, surface storage, and the rate of seal formation. During short storms, crusting occurred more rapidly on the lower slope angles and the hydraulic conductivity of the seal was the dominant influence, so infiltration rate increased with increasing slope angle. Once the seal was well established at all slope angles, the dominant influence of slope angle was on overland flow depth and surface storage, and infiltration rate decreased with increasing slope angle.

The influence of slope angle on surface sealing remains largely hypothetical; in none of the studies were micromorphological observations made nor were subseal pressure head gradients measured. The objective of this study was to investigate the influence of slope angle on infiltration rate for interrill conditions: this was accomplished by assessing its effect on surface seal characteristics and surface storage.

\section{Materials and methods}

The soil used in the study is the Pontypool sandy loam (grey brown luvisol) which appeared susceptible to surface crusting in previous experiments (Fox, 1994). It was collected from the top $20 \mathrm{~cm}$ in the A horizon of a well-drained site $30 \mathrm{~km}$ north of Toronto, Canada, and the dominant minerals in the clay fraction are vermiculite and fine-grained mica (Kodama et al., 1993).

Soil samples were sieved to retain aggregates and sediments of less than 4.0 $\mathrm{mm}$. These were packed in $100 \times 40 \times 10 \mathrm{~cm}$ trays by applying successive 2 -cm layers with light compaction and smoothing between layers. The mean bulk density was $1.29 \mathrm{~g} \mathrm{~cm}^{-3}$ (st. $\mathrm{dev} .=0.03 \mathrm{~g} \mathrm{~cm}^{-3}$ ). The trays were then set at one of five slope angles $\left(1.5^{\circ}, 6.5^{\circ}, 11.5^{\circ}, 16.5^{\circ}\right.$, and $\left.21.5^{\circ}\right)$ and subjected to simulated rainfall using a Lechler nozzle type simulator with a fall height of 6 $\mathrm{m}$; the raindrop characteristics were reported to be similar to natural rainfall at an intensity of about $25 \mathrm{~mm} \mathrm{~h}^{-1}$ (Poesen et al., 1990). Actual rainfall intensities ranged from 38.2 to $56.3 \mathrm{~mm} \mathrm{~h}^{-1}$ with a mean of $49.1 \mathrm{~mm} \mathrm{~h}^{-1}$ and standard deviation of $4.71 \mathrm{~mm} \mathrm{~h}^{-1}$. Intensities were generally slightly greater in the lower (outlet) portion of the soil tray, but this appeared to have no influence on the results observed. Rainfall simulations lasted a total of $90 \mathrm{~min}$ and were divided into two distinct measurement periods: a 75-min overland flow measurement period and a 15-min flow velocity measurement period. These will be 
described in detail shortly. Visual observations through the transparent side wall of the soil tray showed that in none of the replications did the wetting front reach the base of the tray. For each slope angle, ten replicates were included.

Control variables such as antecedent soil water content, rainfall intensity, and bulk density were monitored for each simulation. Gravimetric water content samples were taken immediately prior to each simulation, and rainfall intensity was verified after each simulation using 16 standard total rainfall gauges per soil tray.

\subsection{Overland flow and infiltration rates}

Overland flow was collected every 2 min during the first $10-15 \mathrm{~min}$ and every $4-5$ min thereafter. Infiltration rate at any time during the simulation was calculated as the difference between the rainfall input rate and the combined output of overland flow and splash loss. Splash loss was measured using trays attached to the sides of the flume.

\subsection{Subseal pressure heads}

Pressure heads were measured using microtensiometers with ceramic cups having an outer diameter of $2.2 \mathrm{~mm}$ and a length of $11.1 \mathrm{~mm}$ attached by stainless steel and plastic tubing to transducers of one of two ranges, $0-70 \mathrm{~cm}$ or $0-1033 \mathrm{~cm}$. Values were recorded automatically at 1 -min intervals. A range of 4-6 soil trays per slope angle were equipped with seven tensiometers per tray. Tensiometers were located at three positions within the tray: front, middle and back which corresponding to distances of 5,45 , and $55 \mathrm{~cm}$ from the outlet, respectively. For each position there were two depths, 1 and $3 \mathrm{~cm}$, and the middle position had an additional tensiometer at a depth of $5 \mathrm{~cm}$. The tensiometer readings were corrected for differences in gravitational potential.

\subsection{Overland flow and microtopography}

Overland flow velocities were measured using the dye method (Luk and Merz, 1992): measurements were made over a 15-min period after the initial 75 min of rainfall. They were considered to be representative of quasi-equilibrium conditions. Flow velocity was measured over a distance of $20 \mathrm{~cm}$ at three locations within the tray: $10-30 \mathrm{~cm}, 30-50 \mathrm{~cm}$, and $50-70 \mathrm{~cm}$ from the outlet, respectively. The dye method measures maximum surface velocity and the results were converted to mean flow velocity using the conversion factor of Luk and Merz (1992). They found that a conversion factor of 0.34 for unrilled surfaces gave more accurate estimates of mean flow velocity than the more commonly used range of $0.67-0.80$. The description of the flow pattern was facilitated by the use of an overhead video camera during the period when dye was injected into the overland flow. 
Surface roughness was measured using a rod and ruler system (Hudson, 1996) along three transects within the soil tray. The standard deviation of the microtopographic cross-sections was used as an index of the surface roughness (Courault et al., 1993).

\subsection{Micromorphology}

Once the simulations were completed, the trays were covered and allowed to drain freely overnight, and soil samples were taken from the centre area of the tray using Kubiena boxes $(7.5 \times 6.5 \times 4 \mathrm{~cm})$. The samples were air-dried and impregnated with an unsaturated polyester resin (Fox et al., 1993). Upon hardening, the impregnated blocks were cut, polished, and photographed in black and white under ultraviolet light for image analysis. A 'Kontron SEM-IPS image analyser' was used to extract data from six layers of $2.5 \mathrm{~mm}$ thickness each. Pores were divided into three shape categories according to the ratio of pore area to pore perimeter squared (shape $=A / P^{2}$ ), where $A=$ pore area and $P=$ pore perimeter: values greater than 0.04 were classified as rounded, less than 0.04 and greater than 0.015 as irregular, and less than 0.015 as elongate (Bouma et al., 1977; Pagliai et al., 1983). The pores were then subdivided into four size classes according to the equivalent pore diameter (EPD), where $\mathrm{EPD}=2(A / \pi)^{-5}$ for rounded and irregular pores and according to pore width (W) for elongate pores, where $W=1 / 4\left(P-\left(P^{2}-16 A\right)^{-5}\right)$ (Pagliai, 1983; Pagliai et al., 1983; Valentin, 1991; Gimenez et al., 1992). The four size classes were $50-200 \mathrm{~mm}, 200-350 \mathrm{~mm}, 350-500 \mathrm{~mm}$, > $500 \mathrm{~mm}$.

\section{Results}

\subsection{Infiltration rates}

Infiltration approached a constant rate near the end of the 75- min simulation period. Constant infiltration rates were obtained with the Horton regression equation, $I R=I R_{f}+\left(I R_{i}-I R_{f}\right) e^{-k r}$, where $I R_{f}=$ final infiltration rate $(m m$ $\left.\mathrm{h}^{-1}\right), \mathrm{IR}_{\mathrm{i}}=$ initial infiltration rate $\left(\mathrm{mm} \mathrm{h}^{-1}\right), k=$ regression coefficient, and $r=$ cumulative rainfall $(\mathrm{mm})$. The non-linear regressions were carried out using the NLIN procedure of SAS Procedures (1990).

In an analysis of covariance test $\left(R^{2}=0.51\right)$, slope angle had a significant effect $(\alpha=0.05)$ on infiltration. The final infiltration rates were corrected for slight differences in rainfall duration and intensity using least squares means (SAS Procedures, 1990). The general pattern remains unchanged and both measured and corrected infiltration rates are plotted in Fig. 1. Infiltration rate decreased with increasing slope angle until $11.5^{\circ}$ and remained unchanged at steeper slope angles. The relationship was therefore negative and non-linear; 


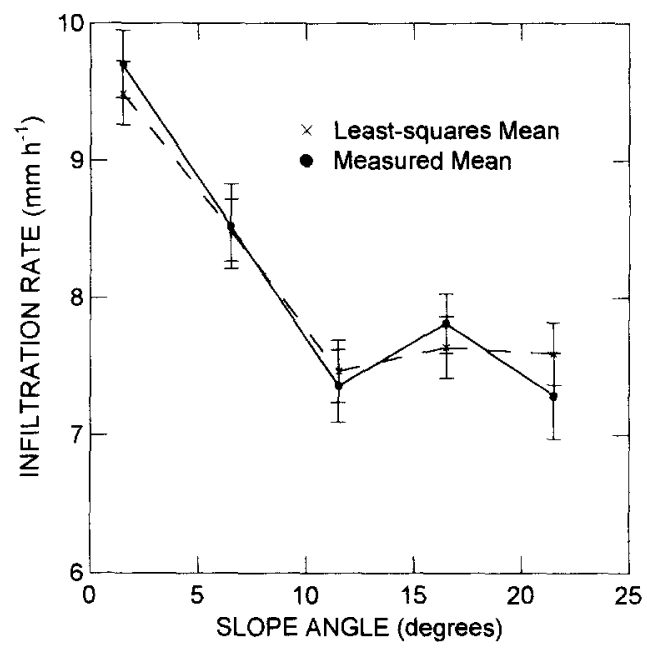

Fig. 1. Decreasing mean measured and least-squares mean final infiltration rates with increasing slope angle (error bars are \pm 1 standard error).

pressure head, micromorphology, and other measurements will be presented before discussing the processes responsible for this relationship.

\subsection{Pressure heads}

Since the seal is of lower hydraulic conductivity than the underlying soil, the subseal zone remains unsaturated and a pressure head gradient develops across the surface seal (Hillel and Gardner, 1969). The ponding pressure head at the surface equals the overland flow depth, and for a given soil, the subseal pressure head will be mainly a function of the hydraulic conductivity of the seal. Seals of lower hydraulic conductivity induce greater pressure head gradients. These relationships are expressed as follows:

$$
q_{\mathrm{c}}=k_{\mathrm{c}}\left[\left(h_{\mathrm{o}}+h_{\mathrm{i}}+z_{\mathrm{c}}\right) / z_{\mathrm{c}}\right]
$$

where $q_{\mathrm{c}}=$ infiltration rate $\left(\mathrm{cm} \mathrm{h}^{-1}\right), k_{\mathrm{c}}=$ seal hydraulic conductivity $(\mathrm{cm}$ $\left.\mathrm{h}^{-1}\right), h_{\mathrm{o}}=$ ponding pressure head $(\mathrm{cm}), h_{\mathrm{i}}=$ subseal pressure head $(\mathrm{cm}), z_{\mathrm{c}}=$ seal thickness $(\mathrm{cm})$. Since the initial packing and subseal soil conditions were similar for all slope angles, the measured pressure heads should reflect the hydraulic conductivity of the surface seal.

Wetting front advance could be observed visually through the tray sidewall. The time required for the wetting front to reach the 1,3 , and $5 \mathrm{~cm}$ depths was obtained from the tensiometer readings. The wetting front was linearly uniform throughout the length of the soil tray with no apparent accumulation near the front soil tray wall. There was no statistical relationship between wetting front advance and slope angle, suggesting that slope angle had little effect on the rate of seal formation in this experiment. 

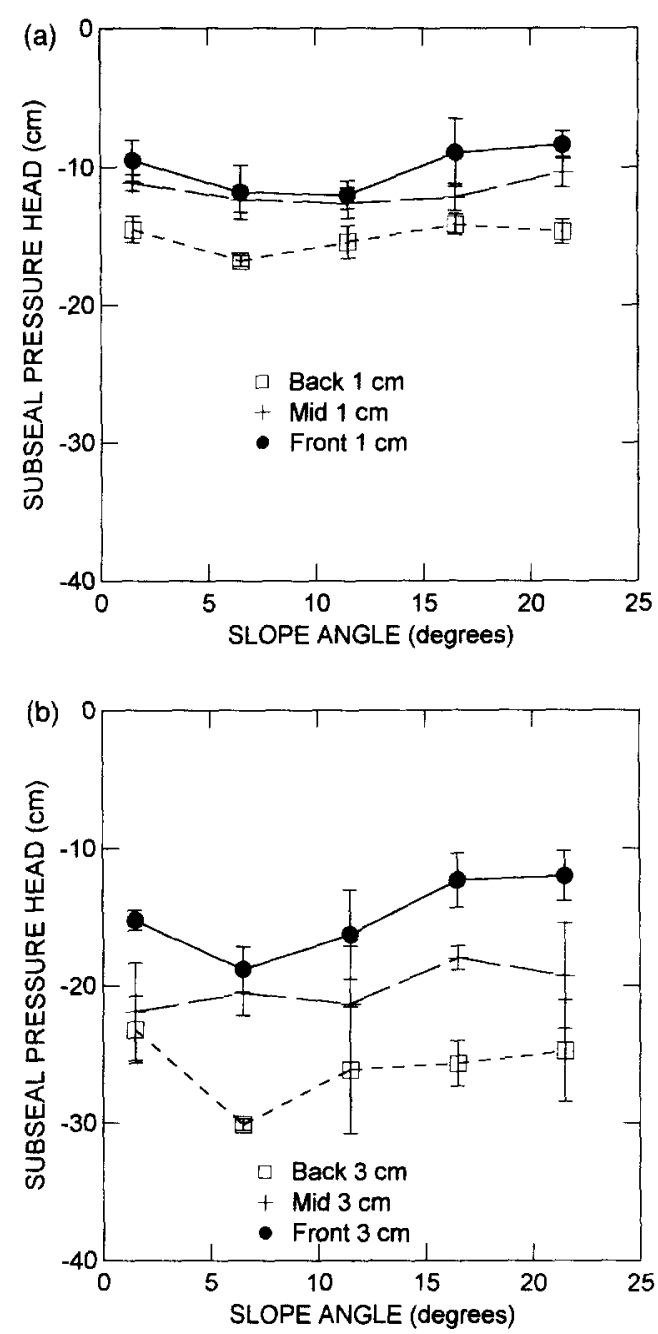

Fig. 2. (a) Mean subseal pressure heads at $1 \mathrm{~cm}$ depth for all slope angles (error bars are \pm 1 standard error). (b) Mean subseal pressure heads at $3 \mathrm{~cm}$ depth for all slope angles (error bars are \pm 1 standard error).

Mean pressure head values recorded after $75 \mathrm{~min}$ of simulated rainfall are shown in Fig. 2 for the the depths of $1 \mathrm{~cm}$ and $3 \mathrm{~cm}$. Results for the $5-\mathrm{cm}$ depth were not included; they clearly show that the wetting front had not reached the base of the tray before the end of the simulation, but they were changing too abruptly to be considered for analysis of the slope angle effect.

Since infiltration rate was greater on the lower slope angles, the expected trend for pressure head should have been corresponding higher values. The curves in Fig. 2, however, suggest that the influence of slope angle on pressure head was either very minor or insignificant. There was no clear or consistent trend with slope angle for any position. Since infiltration rate changed by only 2 
to $3 \mathrm{~mm} \mathrm{~h}^{-1}$ with slope angle, these differences were probably too small to influence the pressure heads enough to be detected in this experiment.

Analyses of covariance tests for each position $\left(R^{2}=0.78,0.82\right.$, and 0.88 for the front, middle, and back, respectively) confirmed that pressure head did not vary with slope angle. Much of the variance was accounted for by tensiometer depth $(\alpha=0.001)$ : pressure heads at $1 \mathrm{~cm}$ were higher than at $3 \mathrm{~cm}$, as can be seen in Fig. 2. This difference may have disappeared over a longer simulation period or it may indicate that the structural crust extended down to a depth of about $1 \mathrm{~cm}$, where the upper tensiometers were located.

\subsection{Micromorphology}

Image analysis of impregnated blocks provides data for pore characteristics in only two dimensions, so it is more accurate to refer to it as a pore area measurement than a porosity measurement, though it is assumed that the two are directly related. For each of the slope angles, pore area and frequency data were collected for successive $2.5 \mathrm{~mm}$ layers down to a depth of $15 \mathrm{~mm}$. As described above, these were classified into three shape categories and four size classes. It was noted that the pores most sensitive to crusting were the intermediate and large sized elongate pores. Both the frequency and area of these pore types decreased near the surface. It was also noted that the frequency and area of round pores was greater in the seal layer than in the undisturbed soil, so it appears that intermediate and elongate pores were sub-divided into smaller rounder pores. This was accompanied by a general decrease in total pore area in the upper layers. Greatest changes occurred in the upper 2.5-mm layer and could be detected visually down to a depth of at least 5.0 to $7.5 \mathrm{~mm}$. The implications of these trends for infiltration modelling will be the subject of a separate publication.

Changes in pore characteristics were observed for all slope angles, but there were no apparent differences associated with slope angle. This was confirmed by an analysis of variance test where depth was the only significant variable ( $\alpha=0.001)$. The image analysis of pore characteristics strongly suggests, therefore, that slope angle had no significant impact on surface seal development.

\subsection{Overland flow depth and surface roughness}

Overland flow velocity was measured over a $20 \mathrm{~cm}$ distance in the lower, middle, and upper portions of the soil trays. Fig. 3 shows that velocity increased downslope and with increasing slope angle. These values were converted to mean overland flow depth using $D=R_{\mathrm{O}} / W V$, where $D=$ mean overland flow depth $(\mathrm{cm}), R_{\mathrm{O}}=$ overland flow rate $\left(\mathrm{cm}^{3} \mathrm{~s}^{-1}\right), W=$ soil tray width $(\mathrm{cm})$, and $V=$ overland flow velocity $\left(\mathrm{cm} \mathrm{s}^{-1}\right)$. It was assumed that flow depth was 


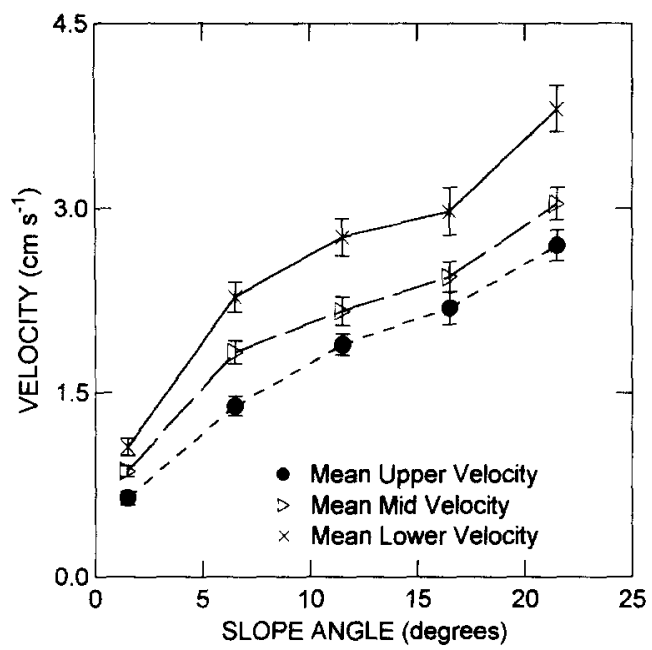

Fig. 3. Overland flow velocity increases with both slope angle and position within the soil tray (error bars are \pm 1 standard error).

uniform across the width of the flume. This was not strictly true, as will be discussed shortly, but the simplification had no implications for the calculation of surface storage volume and mean ponding pressure head. Discharge at the lower boundary of each velocity measurement section was assumed to be proportional to the area upslope. The mean of these values was used to estimate surface storage.

The change in surface storage with slope angle is shown in Fig. 4. The trend is similar to the infiltration rate curves in Fig. 1, and when surface storage was

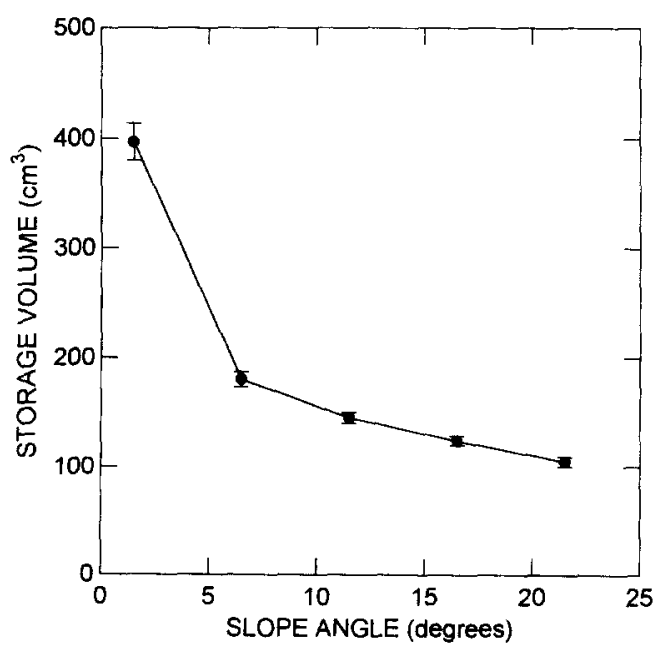

Fig. 4. Decreasing surface storage volume with increasing slope angle (error bars are \pm 1 standard error). 
substituted for slope angle in an analysis of variance test $\left(R^{2}=0.51\right)$, the relationship with final infiltration rate was significant $(\alpha=0.001)$.

The estimated change in mean overland flow depth with slope angle was in the order of about $1 \mathrm{~mm}$, and from visual observations it never appeared to exceed a few $\mathrm{mm}$ within any flow thread. In the presence of a subseal pressure head of about -10 to $-20 \mathrm{~cm}$, an additional positive pressure head at the surface of $1 \mathrm{~mm}$ is insignificant and in itself would not increase the infiltration rate. So the change in overland flow depth did not add sufficient pressure head to account for the increase in infiltration rate observed.

A review of the video images of the dye measurements revealed that overland flow was concentrated in a few large channels at the lower slope angles and in several small fast flowing channels on the steeper slopes. On all slopes, significant portions of the surface were not submerged, and less degraded aggregates protruded from the flow. The implications of this will be taken up in the following discussion.

The surface roughness measured using the rod and ruler system was in the order of about $1 \mathrm{~mm}$ for all slope angles and positions within the soil tray. There were no apparent differences between slope angles and this was confirmed by an analysis of variance test. Therefore, slope angle had no significant impact on the surface roughness index.

\section{Discussion}

Results from the infiltration rates, pressure head measurements, and pore characteristics converge to indicate that slope angle had no significant impact on the rate and intensity of surface seal formation for the range of slope angles observed. After a review of the micromorphology literature dealing with soil crusting, Mualem et al. (1990) concluded that the dominant crusting process influencing infiltration was the decrease in porosity near the surface due to compaction under raindrop impact. They also found there was usually no sharp boundary between the disrupted layer forming the crust and the unaffected soil beneath. In a surface crusted soil, porosity probably decreases non-linearly near the surface, and this trend is consistent with the pore characteristics measured in this experiment. The energy flux density normal to the surface at $21.5^{\circ}$ is roughly $93 \%\left[\left(\operatorname{cosine} 21.5^{\circ} / \operatorname{cosine} 1.5^{\circ}\right)\right]$ of that at $1.5^{\circ}$, and this decrease is probably insufficient to cause significant differences in porosity in the disrupted layer between the two slope angles.

Sharma et al. (1983) suggest that the lower infiltration rates on steeper slopes observed in their experiments were due to shorter detention times since flow velocities are much greater on steeper slopes. However, once steady-state conditions have been reached, there is little or no change in surface storage, so the ponded depth or mean pressure head over the surface is constant. The only 


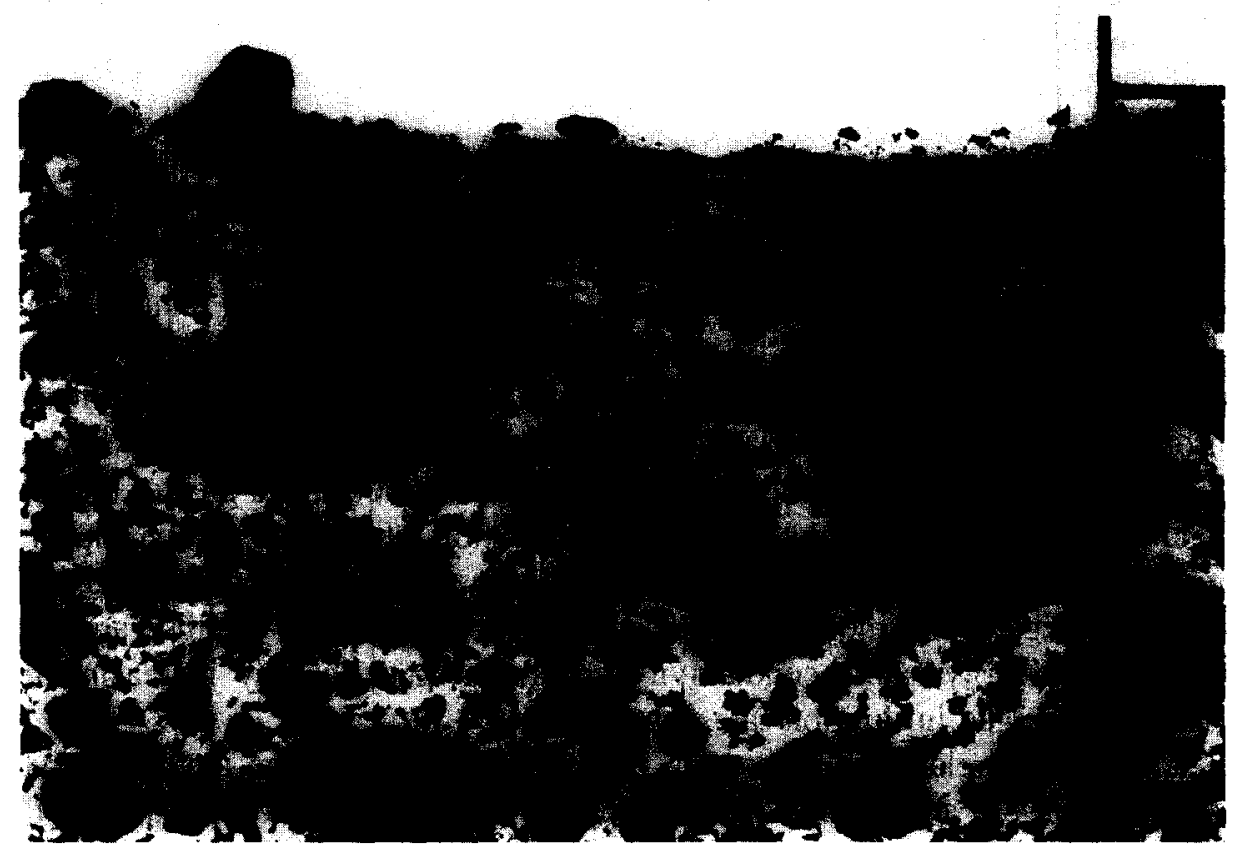

Fig. 5. Photo of impregnated sample: preferential flow may occur around stable aggregate at surface (bar scale at right is in $\mathrm{mm}$ ).

time during which longer detention times can theoretically influence the infiltration rate is at the cessation of rainfall: if the surface water leaves the plots more slowly on gentle slopes, then infiltration will continue for a longer time until the surface is entirely drained. Another explanation must therefore be found.

Small mounds and aggregates protruding above the flow may have had greater hydraulic conductivities than the zones where the aggregates were completely compacted into a structural seal. This was the conclusion of McIntyre (1958, p. 189) who found that "where a stable aggregate or a pebble lay on the surface and was not moved by drop impact, water entered around the aggregate at such a rate that the measured permeability for the area of the cup was increased 10 to 20 times." A photograph of one of the micromorphology samples (Fig. 5) shows how such preferential infiltration can occur in the void around the aggregate at the surface. Similarly, Levy et al. (1988) observed that a surface that was initially plane evolved into a mound and depression type topography under simulated rainfall. The hydraulic conductivity of the mounds was greater than that of the adjoining sedimentary crusts. The changes in overland flow depth with slope angle were estimated at about $1 \mathrm{~mm}$, and this is in the same order as the surface roughness standard deviation, so the increase in depth would be sufficient to submerge significant portions of microtopographic highs. Hence, small changes in flow depth may increase the infiltration rate by 
submerging areas of slightly greater hydraulic conductivity around the more stable aggregates.

\section{Conclusions}

Infiltration rate decreased with increasing slope angle; this trend was consistent with the findings of others (Djorovic, 1980; Luk et al., 1993; Sharma et al., 1983). Slope angle had little or no effect on the characteristics of the surface seal, and the influence of slope angle on infiltration rate occurred dominantly through its influence on overland flow depth. For soils susceptible to surface crusting, the subseal pressure head is generally 20 to 100 times greater than the ponding pressure head, so the increase in infiltration rate at lower slope angles is probably due to small differences in hydraulic conductivity associated with stable aggregates or mounds. With greater overland flow depths, areas of slightly greater hydraulic conductivity are submerged, thereby increasing the spatially averaged infiltration rate.

The positive relationship between infiltration rate and slope angle observed by Poesen (1984) and Bradford and Huang (1992) probably only arises when the seal is breached by rills, and where there is a positive correlation between rill network development or depth and slope angle.

The results observed here also have implications for the relationship between overland flow discharge rate or rainfall intensity and infiltration rate. Infiltration rate has been observed to increase with increasing discharge (De Ploey et al., 1976). Subseal pressure head has also been observed to increase with increasing rainfall intensity (Römkens et al., 1990). Both of these findings may be explained by the submergence of areas of slightly greater hydraulic conductivity as described above.

\section{Acknowledgements}

The authors are grateful to Dr. C. Fox, R. Guertin and E. Bond, Centre for Land and Biological Resources, Agriculture Canada, for their assistance with the micromorphology work. The research was supported by an operating grant to R.B. Bryan from the Natural Sciences and Engineering Research Council, Canada, which is gratefully acknowledged.

\section{References}

Bouma, J., Jongerius, A., Boersma, O., Jager, A., Schoonderbeek, D., 1977. The function of different types of macropores during saturated flow through four swelling soil horizons. Soil Sci. Soc. Am. J. 41, 945-950. 
Bradford, J.M., Huang, C., 1992. Mechanisms of crust formation: physical components. In: Sumner, M., Stewart, B. (Eds.), Soil Crusting: Chemical and Physical Processes. Lewis Publishing, Ann Arbor, Mich., pp. 55-72.

Bryan, R.B., Poesen, J., 1989. Laboratory experiments on the influence of slope length on overland flow, percolation, and rill development. Earth Surf. Process. Landforms 14, 211-231.

Courault, D., Bertuzzi, P., Girard, M.-C., 1993. Monitoring surface changes of bare soils due to slaking using spectral measurements. Soil Sci. Soc. Am. J. 57, 1595-1601.

De Ploey, J., Savat, J., Moeyersons, J., 1976. The differential impact of some soil loss factors on flow, overland flow creep and rainwash. Earth Surf. Process. 1, 151-161.

Djorovic, M.. 1980. Slope effect on run-off and erosion. In: De Boodt, M., Gabriels, D. (Eds.). Assessment of Erosion. Wiley-Interscience, Chichester, pp. 215-225.

Fox, C., Guertin, R., Dickson, E., Sweeney, S., Protz, R., Mermut, A.R., 1993. Micromorphological methodology for inorganic soils. In: Carter, M. (Editor), Soil Sampling and Methods of Analysis. Lewis Publishers, Ann Arbor, Mich., pp. 683-709.

Fox, D.M., 1994. The Influence of Slope Angle on Infiltration Rate, Surface Seal Characteristics, and Soil Loss: A Laboratory Study. Unpublished Ph.D. dissertation, University of Toronto, Toronto.

Gimenez, D., Dirksen, C., Miedema, R., Eppink, L.A.A.J., Schoonderbeek, D., 1992. Surface sealing and hydraulic conductances under varying-intensity rains. Soil Sci. Soc. Am. J. 56, 234-242.

Hillel, D., Gardner, W.R., 1969. Steady infiltration into crust-topped profiles. Soil Sci. 108, $137-142$.

Hudson, N.W., 1996. Mesures de terrain de l'érosion et de l'écoulement des eaux de surface. Bull. Pédol. FAO, 68, Rome, 153 pp.

Kodama, H., Ross, G., Wang, C., MacDonald, K., 1993. Clay Mineralogical Database of Canadian Soils. Technical Bulletin 1993-1E, CLBRR contribution 92-82, Research Branch, Agriculture Canada.

Levy, G.J., Berliner, P., Du Plessis, H., Van der Watt, H., 1988. Microtopographical characteristics of artificially formed crusts. Soil Sci. Soc. Am. J. 52, 784-791.

Luk, S., Merz, W., 1992. Use of the salt tracing technique to determine the velocity of overland flow. Soil Technol. 5, 289-301.

Luk, S.H., Cai, Q., Wang, G.P., 1993. Effects of surface crusting and slope gradient on soil and water losses in the hilly loess region, North China. Catena Suppl. 24, 29-45.

McIntyre, D., 1958. Permeability measurements of soil crusts formed by raindrop impact. Soil Sci. $85,185-189$.

Mualem, Y., Assouline, S., Rohdenburg, H., 1990. Rainfall induced soil seal, a critical review of observations and models. Catena 17, 185-203.

Nassif, S., Wilson, E., 1975. The influence of slope and rain intensity on overland flow and infiltration. Hydrol. Sci. Bull. 20, 539-553.

Pagliai, M., 1983. Caratterizzazione della porosita del terreno mediante l'analizzatore ottico-elettronica di immagine Quantimet 720. Agrochimica 27, 113-122.

Pagliai, M., La Marca, M., Lucamante, G., 1983. Micromorphometric and micromorphological investigations of a clay loam soil in viticulture under zero and conventional tillage. J. Soil Sci. 34, 391-403.

Poesen, J., 1984. The influence of slope angle on infiltration rate and Hortonian overland flow volume. Z. Geomorphol. N.F., Suppl.Bd. 49, 117-131.

Poesen, J., Ingelmo-Sanchez, F., Mücher, H., 1990. The hydrological response of soil surfaces to rainfall as affected by cover and position of rock fragments in the top layer. Earth Surf. Process. Landforms 15, 653-671. 
Römkens, M.J.M., Prasad, S.N., Parlange, J.-Y., 1990. Surface seal development in relation to rainstorm intensity. Catena Suppl. 17, 1-11.

SAS Procedures, 1990. SAS Institute Inc., Box 8000, Cary, NC, 27512-8000.

Sharma, K., Singh, H., Pareek, O., 1983. Rainwater infiltration into a bare loamy sand. Hydrol. Sci. J. 28, 417-424.

Valentin, C., 1991. Surface crusting in two alluvial soils of northern Niger. Geoderma 48 , $201-222$.

West, L., Chiang, S., Norton, L., 1992. The morphology of surface crusts. In: Sumner, M., Stewart, B. (Eds.), Soil Crusting: Chemical and Physical Processes. Lewis Publishing, Ann Arbor, Mich., pp. 73-92. 